Double Learning or Double Blinding

-An investigation of vendor private information acquisition and consumer learning via online reviews

\title{
Nan Hu
}

Howe School of Technology Management

Stevens Institute of Technology

1 Castle Point Terrace, Hoboken, NJ 07030,

United States

nan.hu@stevens.edu

\section{Kevin E. Dow}

Nottingham University Business School China

University of Nottingham Ningbo China

199 Taikang East Road, Ningbo, 315100, China

Kevin.dow@nottingham.edu.cn

\author{
Alain Yee Loong Chong* \\ Nottingham University Business School China \\ University of Nottingham Ningbo China \\ 199 Taikang East Road, Ningbo, 315100, China \\ Alain.chong@nottingham.edu.cn
}

\section{Ling Liu}

Department of Accounting and Finance

University of Wisconsin-Eau Claire

05 Garfield Avenue, WI 54701

United States

liul@uwec.edu

\section{*Corresponding author}




\title{
Double Learning or Double Blinding -An investigation of vendor private information acquisition and consumer learning via online reviews
}

\begin{abstract}
In this paper, building upon information acquisition theory and using portfolio methods and system equations, we made an empirical investigation into how online vendors and consumers are learning from each other, and how online reviews, prices, and sales interact among each other. First, this study shows that vendors acquire information from both private and public channels to learn the quality of their products to make price adjustment. Second, for the more popular products and newly released products, vendors are more motivated to acquire private information that is more precise than the average precision to adjust their price. Third, we document a full demand-mediation model between rating and price. In other words, there is no direct linkage between price and rating, and the impact of rating on price (the vendor learning) as well as the impact of price on rating (the consumer learning) are all through demand. Our results show that there is no fundamental difference between the pricing decisions with and without the consumer generated contents. The price is still driven by the supply and demand relationship and vendors only adjust their price in response to review change when those reviews impact sales. We proposed either the impact of reviews has been incorporated into sales or reviews are less truth worthy due to potential review manipulation. Given the complicate situation, we call for further study to unveil this double learning process with double blinding results.
\end{abstract}

Keywords: online reviews, word-of-mouth, online product reviews, double-learning, analyst forecast 


\section{Introduction}

Pricing has been a long-standing topic among various research communities, such as economics, information systems, and marketing. Previous research has studied different aspects of online price, such as comparing the pricing level, pricing change frequency, pricing change amount of the online channels to those of the off-line channels (Amrouche and Yan, 2015). However, these researches treat price adjustment as a black-box without a fully understanding of how firms make price adjustment decision based on information from Internet.

As one of the most exciting trends in computing today, consumer generated social media, holds the potential to change how information is accessed and presented, how knowledge is processed and extracted, how daily operation is conducted and how strategies are executed, and how pricing is determined and adjusted (Gu and Ye, 2014; Liu et al., 2015). As online reviews increasingly affecting the ecommerce demand, transforming the nature of the competition, and alternating the processes by which firms' pricing decisions are made and implemented, it is timely and importantly to have a substantial understand of firm pricing decision with the presence of user generated contents-online reviews.

The idea of better serving customer needs is rooted in the age-old notion of listening to the customer to co-create products and services. It is widely recognized today that companies that can better understand their customers' needs will thrive in the competitive landscape (Jiang and Zhou, 2014). This requires companies to digest the richness quality and valuation information from today's online consumer generated media and make the right pricing decision (Ngai et al., 2015). We argue that it is crucial and timely to develop a systematic framework to study the learning behavior of the consumer and vendor simultaneously.

Till now, most of these studies only consider one side of the learning equation, i.e. only consumers learn quality information embedded inside online reviews. For example, there is an emerging literature studying whether consumers read, appreciate, and use the quality information embedded inside online reviews and respond accordingly-termed consumer learning effect. To document this consumer learning effect, a variety of regression models have been used to link online product reviews with product 
sales (e.g., Chen et al. 2004, Chevalier and Mayzlin 2006, Dellarocas et al. 2004, Godes and Mayzlin 2004, Hu et al. 2008, Li and Hitt 2008). The positive relation between the average (mean) score of these reviews and product sales revealed that consumers do act upon online reviews to make purchase decision.

An implicit assumption in the extant research is that vendors ignore the rich semantic contents of online consumer reviews and does not adjust their price accordingly. To better serve their customers' needs, rational vendors should not ignore the rich quality information embedded in online reviews. Before releasing a product to online market, vendors might only have some rough idea about the value or quality of that product through their initial market research such as consumer surveys, focus group study, or price of similar products. They do not know the exact price number that they should charge in order to maximize their profit. To get started, under such a circumstance and for such a product, vendors will charge a price that reflects their belief of consumers' valuation on that product at that moment. Then they might revise their assessment through observing the demand they received or the reviews posted by the consumers who bought and used that product. Through such a learning process, vendors can get a better valuation estimation of their product. In other words, vendors might adjust their product price in responding to the change of the sales or change of the online consumer reviews, which we term vendor learning effect. The learning loop does not stop here. Consumers might (re)learn the product's quality based on the price adjustment made by online vendors to change their perceived quality, make further purchase decision, and write a better consumer review, which we refer as consumer learning.

Given the increasing importance of online user generated contents, it is timely and vital to put both sides of the learning equations together to understand how vendors and consumers are learning from each other to derive quality information from online reviews to make purchase or pricing decision. Therefore, our research questions are as follows:

1. Are online reviews value-relevant to online vendors? In other words, are vendors also learning from online reviews? 
2. What kind vendors are more motivated to acquire private information with higher precision to learn the quality information of a product?

3. How are online vendors learning quality information from online reviews to make price adjustment? Do they adjust their price based on review change or they only respond to the demand change?

4. Can vendors influence the online reviews by change price? Are consumers influenced by the pricing movement made by online vendors? Do prices drive ratings, and/or vice versa? Are rating change and price change concordant with each other?

Based on the secondary data collected at Amazon.com from August 2005 to February 2006, our empirical evidence indicates that vendors do read and are acting upon online reviews to make price adjustment decision in order to increase their revenue. Therefore, our findings provide great insights on how vendors mange their customer relationship and product marketing and pricing strategies.

The paper makes five key contributions: First, we show that vendors and consumers are learning from each other to make their pricing or purchase decisions simultaneously. The vendor side learning and the consumers' learning from the vendor's learning have been ignored by previous research. Based on system equations, we are able to unveil the simultaneous consumer and vendor learning effect. Second, we demonstrate that Amazon market behaves like a stock market. In this market, online reviews serve a role similar to public announcements. And vendors acquire information from both private and public channels to learn the quality of their products to make price adjustment decisions. Third, we document what kind vendors are more likely to engage on private information acquisition. For the more popular products and products newly released to Amazon market, vendors are more motivated to acquire private information that is more precise than the average precision to adjust their price. Fourth, we illustrate that the fundamental supply and demand relationship is still the main driver for online price. Vendors only adjust their price in response to the sales change instead of review change. Our interpretation is that either the impact of reviews have been incorporated into sales, or for vendors online reviews might be a noisy 
signal because online reviews might be written by the authors, vendors' competitors, or publishers instead of the actual customers. Thus unless online reviews really impact sales, vendors will not make the necessary price adjustment accordingly. Last, we demonstrate that the consumers are smart as well and do not change their rating in response to the price adjustment made by vendors. To conclude, we document a full demand-mediation model between rating and price. In other words, there is no direct linkage between price and rating, and the impact of rating on price (the vendor learning) as well as the impact of price on rating (the consumer learning) are all through demand.

The rest of the paper is organized as follows. In Section 2, we study the information contents of online reviews. We compare the difference between Amazon market and stock market to build our theoretical framework and research hypotheses to study whether vendors acquire information from both public and private channels in response to online consumer reviews. Using system equation, Section 3 addresses the issue how vendors and consumers are learning from each other and how vendors make pricing adjustment decision. Section 4 discusses the limitations and concludes with suggestions for future research.

\section{Are Firms Acquiring both Public and Private Information in Response to Online Reviews?}

\subsection{Backgrounds and Hypotheses}

The Internet has fundamentally changed the competition environment of firms, offering business and consumers an increasingly powerful channel to acquire product quality, price, and demand information. With the fast adoption of web 2.0 driven user communities and the prevalent implementation of online reviews, a large number of consumers resorting to use these consumer generated media to voice their opinions on the products they have purchased (Gaikar et al., 2015). Marketing power is no longer restricted to a local context, but can reach anyone connected through the Internet. Given the enormous real-time product quality information vendors can extract from online consumer reviews, this might lead to a more dramatic price competition as well as a faster price adjustment. With menu costs previously preventing rapid price from happening getting eliminated, and with the delay of receiving users feedbacks 
getting removed, vendors might be able to make instantaneous price adjustment in response to the realtime new feedbacks, such as online reviews. However, is that true?

Previous studies have studied different aspects of Internet pricing, such as the absolute price level, price adjustment frequency, price adjustment amount of online versus those of offline, to answer whether Internet might lead to a more dramatic price competition and higher price rigidity. On the price level side, several empirical studies have compared the price levels between conventional offline firms and online firms. However, the results are inconclusive. Some researchers concluded that on average, firms selling through online market might be able to charge a higher price comparing to the offline market (Cortese and Stepaneck 1998, Erevelles et al. 2001). However, others claimed the opposite (Ancarani and Shankar 2002, Brynjolfsson and Smith 2000, Morton et al. 2001). For example, by comparing the prices of books, CDs, and software sold on the Internet to those on conventional offline channels in 1996 and 1997, Bailey (1998) concluded that on average vendors charged higher prices in online channels for each product category. His interpretation is the value adding service provided by online channels, such as convenience, leads to a higher price. However, by examining prices for books and CDs sold through the Internet and conventional channels in a later period (1998 and 1999), Brynjolfsson and Smith (2000) found that the Internet had lower unit prices because the online market had become more efficient. Morton et al (2001) reached a similar conclusion by analyzing the online automobiles price versus offline dealer price.

On the price rigidity side, Bergen et al. (2005) studied the Internet price rigidity using data of 377 books collected from the Amazon.com and Barnes and Noble. They documented that on average, there was much less frequent price adjustment on these websites and the price-change activities varied across product categories. Based on the price of CD titles, Lee et al. (2003) found that the price adjustment of Internet retailers was much smaller than offline counterparts; and the price dispersion of Internet retailers was also lower than that of offline retail stores. However, to my best knowledge, all these researches treat price change as a black-box without fully understanding how vendors really make such a decision. For this study, we open this black-box by investigating how vendors use both public and private information to make price adjustment decision. Brynjolfsson and Smith (2000) believe that pricing is likely to be 
frictionless on the Internet. If that is the case, it suggests that applying pricing models that are financialmarket-like provides the functionality of the stock markets in firms' ability to adjust prices (Bergen et al., 2005).

So does online review market really behalf as a stock market? What is the difference and similarity between stock market and Amazon market? If we treat online market as stock market, online consumer reviews as public information announcements, such as earning announcements, analyst forecasts or forecast revision, then we should expect that both customers and vendors to use the quality information embedded inside the online reviews to make their own decisions. Table 1 compares the learning process of stock market to online review market. For the investors of stock market, their goal is to identify the intrinsic value of a stock using both public available information (such as earning announcement) and/or private information (such as inside news); while for the vendors of online review market, their goal is to identify the intrinsic value of an item and decide whether to change the price or not based on both publicly available information (such as online reviews) and/or private information (such as focus group study or survey). So both entities have information acquisition needs. And both parties go through learning processes using information coming from various channels.

Table : 1 Learning Process Comparison Between Amazon Market and Stock Market

\begin{tabular}{|c|c|c|c|}
\hline & Stock Market & $\begin{array}{l}\text { Consumer on } \\
\text { Amazon.com }\end{array}$ & Vendor on Amazon.com \\
\hline Goal & $\begin{array}{l}\text { Identify the intrinsic value of a } \\
\text { stock , and decide whether to buy } \\
\text { or to sell that stock based }\end{array}$ & $\begin{array}{l}\text { Identify the intrinsic quality } \\
\text { of an item and decides } \\
\text { whether to buy that item. }\end{array}$ & $\begin{array}{l}\text { To identify the intrinsic price of } \\
\text { an item, a vendor setups an } \\
\text { initial price and see how the } \\
\text { market responds to his product } \\
\text { to decide whether to change the } \\
\text { price and how much }\end{array}$ \\
\hline $\begin{array}{c}\text { Information } \\
\text { Source }\end{array}$ & $\begin{array}{l}\text { Public (earning announcement, } \\
\text { analyst forecast etc) or private } \\
\text { information (e.g. inside } \\
\text { information) }\end{array}$ & $\begin{array}{l}\text { Public (e.g. online reviews) } \\
\text { or private information (e.g. } \\
\text { friends' opinion) }\end{array}$ & $\begin{array}{l}\text { Public (e.g. online reviews) or } \\
\text { private information (e.g. focus } \\
\text { group study) }\end{array}$ \\
\hline Participants & $\begin{array}{l}\text { Multiple buyers and sellers of } \\
\text { heterogeneous valuation }\end{array}$ & $\begin{array}{l}\text { Multiple buyers with } \\
\text { heterogeneous tastes and } \\
\text { quality valuation }\end{array}$ & $\begin{array}{l}\text { Multiple vendors selling } \\
\text { products with heterogeneous } \\
\text { quality valuation }\end{array}$ \\
\hline Procedures & $\begin{array}{l}\text { 1. Consumers acquire public } \\
\text { information, such as balance } \\
\text { sheet, income statement, and }\end{array}$ & $\begin{array}{l}\text { 1.Consumers read public } \\
\text { information, such as author, } \\
\text { publishers, subject, the return }\end{array}$ & $\begin{array}{l}\text { 1.Vendors read public } \\
\text { information, such as online } \\
\text { reviews to determine the }\end{array}$ \\
\hline
\end{tabular}




\begin{tabular}{|c|c|c|c|}
\hline & $\begin{array}{l}\text { cash flow statement to form their } \\
\text { valuation of one particular stock. } \\
\text { 2. Consumers acquire private } \\
\text { information to fine turn their } \\
\text { evaluation } \\
\text { 3. Compare the current stock } \\
\text { price to the estimated to make } \\
\text { buy/sell decision. }\end{array}$ & $\begin{array}{l}\text { policy, product warrant, } \\
\text { online reviews, etc to } \\
\text { determine the quality of a } \\
\text { product } \\
\text { 2. Consumers acquire private } \\
\text { information (such as seeking } \\
\text { friends' opinions) to adjust } \\
\text { their evaluation. } \\
\text { 3. Put all the information } \\
\text { together and form an intrinsic } \\
\text { quality or value independent } \\
\text { of the current sale price. }\end{array}$ & $\begin{array}{l}\text { quality of a product } \\
2 . \text { Vendors collect private } \\
\text { information, such as focus } \\
\text { group interview to turn their } \\
\text { evaluation, } \\
\text { 3. Put all the information } \\
\text { together and decide whether to } \\
\text { change price or not, and how } \\
\text { much to change. }\end{array}$ \\
\hline $\begin{array}{c}\text { Driving } \\
\text { Forces }\end{array}$ & New information & $\begin{array}{l}\text { Pricing change and consumer } \\
\text { rating change to decide } \\
\text { whether to buy or not. }\end{array}$ & $\begin{array}{l}\text { Sales change and review } \\
\text { change to decide whether to } \\
\text { change price }\end{array}$ \\
\hline $\begin{array}{l}\text { How to test } \\
\text { private } \\
\text { information } \\
\text { acquisition }\end{array}$ & $\begin{array}{l}\text { Trading volume associated with } \\
\text { absolute price change reflects } \\
\text { pre-announcement private } \\
\text { information and trading volume } \\
\text { independent of absolute price } \\
\text { change reflects event-period } \\
\text { private information }\end{array}$ & & $\begin{array}{l}\text { Absolute price change } \\
\text { associated absolute rating } \\
\text { (sales) change reflects pre- } \\
\text { announcement private } \\
\text { information and absolute price } \\
\text { change independent of absolute } \\
\text { rating sales) change reflects } \\
\text { event-period private } \\
\text { information }\end{array}$ \\
\hline
\end{tabular}

Conceptually, in this study, we treat an online store with online reviews as a stock market and individual items in this online store as equivalent of individual stocks. When facing pre-existing public information and upcoming announcements, there are deep learning effects driven by information needs on both markets. On the stock market, in response to a public news announcement, such as an appointment of new CEO, individual investors might actively acquire private information, such as talking to friends in that company to find more information about this CEO. Through this information acquisition process, they can better assess the driver for this new movement, resulting in an adjusted intrinsic valuation about that stock; While, for the vendors on the Amazon market, they are actively learning from both public and private information channels to make price adjustment decision in response to online review "announcements" as well. For example, when facing a decreasing consumer rating for its online products, vendors should not immediately conclude that they are charging a higher price, thus make an immediately price adjustment. They might conduct survey to find the really underlying reason. Combining these private information with the rating change or sales change information, vendors can make the final 
decision about the direction and the magnitude of the change. While on consumer learning side, the price vendors charged, the price adjustment (direction and magnitude) vendors made, and the online reviews left by previous customers all have the potential to change consumers' intrinsic value of a product as well. Next, we focus on studying the vendor side learning by comparing the information acquisition effect on the online review market and stock market to build our theory foundations (Figure 1).

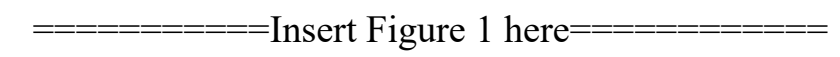

Fig 1 Information Acquisition Effect on Stock Market and Amazon Market

As Figure 1 points out, on stock market, besides public information channel, investors can acquire stock valuation information through private information channel to help them to determine the intrinsic value of a stock; while on online review market, when facing review and sales information, vendors can also acquire private information to determine whether and how much they need to make price change. On stock market, the main reason for acquiring private information is that for the same announcement (public information), the better informed investors (those acquire private information with higher precise than the average precision) economically will benefit more than less informed investors (Kim and Verrecchia 1997). However, given there is a cost for private information acquisition, investors of big firms or firms with higher percentage of institutional ownership will be more likely to engage on private information acquisition (Schneible and Stevens 2005) because the return to private information increases with firm size (Atiase 1980) and institutional ownership.

Following a similar line of argument, we propose that on Amazon market, to better serve their customers, vendors need to make the price adjustment based on the public information, such as the review posts, the rating change, or the sales (demand) change ${ }^{\mathrm{i}}$, or the private information, such as results from focus group study. In this paper, we use sales rank instead of sales because Amazon does not provide the actual sales number. For sales rank, that information is public available. This approach is consistent with similar previous researches such as Nan et al. (2008), Shen et al. (2015) and Chong et al. (2016). However, for the same magnitude of rating or sale change, the pricing adjust level might vary across vendors due to the different 
level of private information vendors holding. The main reason for acquiring private information in Amazon is also due to economic consequence. In Amazon, for the same level of announcement (e.g. same magnitude of rating score change or sales change), the better informed vendors economically will benefit more than less informed vendors because they can adjust price to a better level that suits their customer needs. Private information here can mean conducting focus group study, sending survey to customers, or getting professional consulting group involvement to have a more accurate picture about customers' valuation of their product. However, just as in the stock market, the private information acquisition for these online vendors is not free. We hypothesize that since there is a cost for private information acquisition, vendors selling more popular items or newly released items have a higher incentive to engage on private information acquisition (Figure 2).

$==========$ Insert Figure 2 here $==========$

Fig 2 Time Learning Effect and Popularity Learning Effect

\section{Popularity Learning Effect and Time Learning Effect}

The $\mathrm{X}$-axis of Figure 2 represents the time learning effect, while the Y-axis shows the popularity learning effect. As we can see, for different items, vendors have higher incentive to engage in private information acquisition for popular items because economic wise, they can benefit more from such learning. As for the time driven learning effect, as items change from just getting released to Amazon market to the stage that they become an aged item, the available public information as well as the informativeness of these public information keeps increasing, thus vendors will have less incentive to acquire private information for aged items.

\section{Pre-announcement and within Event Period Private Information Acquisition}

Investors can acquire private information both before a public announcement and within announcement period. Analytically Kim and Verrecchia (1997) show that trading volume associated with absolute price change reveals pre-announcement private information acquisition; while trading volume independent of absolute price change reflects the private information acquisition within event period. And 
with the increase in the private information acquisition, the volume reaction associated with or independent of absolute price change will increase as well (Kim and Verrecchia 1991 and 1994).

Follow the same argument, we proposal that on the online environments, facing the online review "announcements", vendors will acquire private information before and within announcement period as well. Before announcement meaning before new online reviews come or before putting a product to market, vendors might conduct private market researches, focus group, etc to better access the market demand and valuation of the products they are selling. Within announcement measures after reading new online reviews, vendors might change their belief. To further validate that, they might conduct private market research to decide whether to make the necessary price adjustment.

And cross-sectional the pre-announcement and within-event period private information acquisition vary across vendors. Across different vendors, those selling more popular items are more motivated to acquire private information; and for the same item across time horizon, at the early stage right after a product gets released to the market, vendors are more motivated to acquire private information as well. Such different level private information acquisition will manifest through the relation between absolute price changes and absolute review change (or absolute sales change) (Figure 1). In other words, both the magnitude of rating change and sales change across different periods might serve as the signal of the consumer valuation change. Assume that there are two groups of vendors; the first group sells very popular items; while the second group sells very un-popular items. Because the vendors in the first group selling more popular items are more motivated to acquire more private information above normal precision, thus holding other information the same, the variance of the information holding across the vendors in the first group definitely is higher than that of the second group. Thus, we should observe a bigger magnitude of price movement in the first group than in the same group.

Besides private information acquisition, the precision of the pre-announcement public information also impact the market volume response. Kim and Verrecchia (1994) proposes that an increase on the precision of the pre-announcement public information will decrease the volume reaction independent of absolute price change; while at the same time it has no impact on the volume reaction 
associated with absolute price change Kim and Verrecchia (1991b). We proposal this will hold for the relation between absolute price change and absolute rating (sales) change on the online review market as well. Furthermore, previous study on the price rigidity proposes that most vendors keep their price position after a 3-month period; however, they are more likely to change their price as time elapses (Oh and Lucas, 2006).

Table 2A: Relations between Absolute Price Change and Popularity Effect

\begin{tabular}{|c|c|c|}
\hline Item & $\begin{array}{c}\text { Absolute Price Change } \\
\text { Associated with Absolute Rating } \\
\text { (Sales) change }\end{array}$ & $\begin{array}{c}\text { Absolute Price Change } \\
\text { Independent of Absolute Rating } \\
\text { (Sales) change }\end{array}$ \\
\hline $\begin{array}{c}\text { Less popularity (More Silence) item, less } \\
\text { private information acquisition }\end{array}$ & - & - \\
\hline $\begin{array}{c}\text { Decrease in the pre-announcement public } \\
\text { information precision }\end{array}$ & No Effect \\
\hline Price rigidity & \multicolumn{2}{|c|}{ With time elapsed, it is more likely to have price change $(+)$} \\
\hline
\end{tabular}

Table 2B: Relations between Absolute Price Change and Age Effect

\begin{tabular}{|c|c|c|}
\hline Item & $\begin{array}{c}\text { Absolute Price Change } \\
\text { Associated with Absolute Rating } \\
\text { (Sales) change }\end{array}$ & $\begin{array}{c}\text { Absolute Price Change } \\
\text { Independent of Absolute Rating } \\
\text { (Sales) change }\end{array}$ \\
\hline $\begin{array}{c}\text { More aged item, less private information } \\
\text { acquisition }\end{array}$ & - & - \\
\hline $\begin{array}{c}\text { Increase in the pre-announcement public } \\
\text { information precision }\end{array}$ & No Effect & - \\
\hline Price rigidity & With time elapsed, it is more likely to have price change $(+)$ \\
\hline
\end{tabular}

Table 2A and Table 2B summarize the different forces having impact on the price movement in response to absolute rating (sales) change on Amazon market, including private information acquisition, public information precision, and price rigidity. Given the same level of information (the magnitude of sales change or rating change) vendors received, different vendors might respond with different magnitudes of price adjustment due to the private information they are holding or the precision of the public information. As we can see, that for time related learning effect, with items become aged, the private information acquisition between events and the pre-announcement public information precision work toward the same direction on the absolute price reaction independent with absolute rating (review) 
change. For the popularity related learning effect, on the absolute price reaction independent with absolute rating (review) change, with items become less popular, the private information acquisition between events works toward different direction from the pre-announcement public information precision. However, due to the price rigidity, for both time driven and popular driven learning, the ultimate direction of the absolute price reaction independent of absolute rating (review) change depends on the relative magnitude among private information acquisition effect, the public information effect, and the price rigidity. And the ultimate sign of the absolute price reaction associated with absolute rating (review) change depends on the relative magnitude between private information acquisition effect and precision of the public information.

We expect that the public information of the more popular items or more aged item to be more precise than that of the less popular items or newly released item. Assuming that review change or sales change do have information contents, we have the following hypotheses:

H1: Absolute price adjustment associated with absolute sales (or rating) change decreases with item age if the return to private information effect dominates and increases with item age if the price rigidity effect dominates.

H2: Absolute price adjustment independent of absolute sales (or rating) change decreases with item age if the net results of the return to private information effect and the precision of public (pre-announcement) information effect dominates and increases if the price rigidity effect dominates.

H3: Absolute price adjustment associated with absolute sales (or rating) change decreases with item popular decreases if the return to private information effect dominates and increases with item popular decreases if the price rigidity effect dominates.

H4: Absolute price adjustment independent of absolute sales (or rating) change decreases with item popular decreases if the return to private information effect dominates and increases if the net results of the precision of public (pre-announcement) information effect and price rigidity effect dominates. 


\subsection{Empirical Regulation}

To test our hypotheses, we adopt the following regression model to link absolute price to absolute sales or rating change (as follows). Again, the magnitude of the absolute price or sales change sends signal to vendors about the market valuation, combining this with the level of the private information vendors hold, vendors will respond accordingly.

\section{| LogPriceChg $\left.\right|_{\mathrm{it}}=$}

$\alpha_{0}+\alpha_{1}|\operatorname{LogSaleRankChg}|_{\mathrm{it}-1}+\alpha_{2} \mid$ AvgRatingChg $\left.\right|_{\mathrm{it}-1}+\alpha_{3} \log [\text { Silence }]_{\mathrm{it}-1}+\alpha_{4} \log [\mathrm{T}]_{\mathrm{it}-1}$

$\alpha_{5}|\operatorname{LogSaleRankChg}|_{\mathrm{it}-1} * \log [\text { Silence }]_{\mathrm{it}-1}+\alpha_{6} \mid$ AvgRatingChg $\left.\right|_{\mathrm{it}-1} * \log [\text { Silence }]_{\mathrm{it}-1}$

$\alpha_{7}|\operatorname{LogSaleRankChg}|_{\mathrm{it}-1} * \log [\mathrm{T}]_{\mathrm{it}-1}+\alpha_{8} \mid$ AvgRatingChg $\left.\right|_{\mathrm{it}-1} * \log [\mathrm{T}]_{\mathrm{it}-1}+\alpha_{9} \operatorname{DvdDummy}_{\mathrm{i}}+\varepsilon_{\mathrm{it}}$

Where

$\mid$ LogSaleRankChg $\left.\right|_{i t}=$ the absolute difference between the natural log of Sales Rank at time $t$ and that at $\mathrm{t}-1$ for the $\mathrm{i}^{\text {th }}$ product

$|\operatorname{LogPriceCh}|_{\mathrm{it}}=$ the absolute difference between the natural log of price at time $\mathrm{t}$ and that at $\mathrm{t}-1$ for the $\mathrm{i}^{\text {th }}$ product

| AvgRatingChg $\left.\right|_{\mathrm{it}-1}=$ Absolute rating change from $\mathrm{t}-1$ to $\mathrm{t}$ for the $\mathrm{i}^{\text {th }}$ product

$\log [\text { Silence }]_{\mathrm{it}}=$ the natural $\log$ of the Silence variable of the $\mathrm{i}^{\text {th }}$ product at time $\mathrm{t}$, where

Silence $=\mathrm{T} /$ Number of Reviews, smaller $\log [\text { Silence }]_{\mathrm{it}}$ value represents items with higher popularity.

$\log [\mathrm{T}]_{\mathrm{it}}=$ How long the $\mathrm{i}^{\text {th }}$ product has been released to Amazon market

The coefficients on the variable $\log [\mathrm{T}]$ and $\log [$ Silence $]$ capture the between events private information acquisition related to time driven learning and popularity driven learning. They are the results of the net effect among private information acquisition during the event period, the precision of the preannouncement information, and the price rigidity (Hypothesis 2 and 4). The coefficients on the interaction terms $\mid$ AvgRatingChg $\mid * \log \left[\right.$ Silence], $\mid$ LogSaleRankChg $\mid{ }^{*} \log [$ Silence $], \mid$ AvgRatingChg $\mid{ }^{*} \log [\mathrm{T}]$ and $|\operatorname{LogSaleRankChg}| * \log [\mathrm{T}]$ capture the before event private information acquisition related to time driven learning and popularity driven learning; they are the results of the trade-off between private information acquisition before public announcement and the price rigidity (Hypothesis 1 and 3). 


\subsection{Data Collection}

We collected our data from Amazon.com's Web Service (AWS). These data allow us to examine the how consumers and vendors are learning from each other and how vendors adjust price based on both public and private information. A panel of books and DVDs was randomly chosen in July 2005. We used panel data because compared with cross-sectional data, panel data are more suitable for studying the dynamics of adjustments because they control for unobserved heterogeneity (Baltagi 2001, Boulding 1990). For each item, we collected its price, sales, and review information for several months at approximately threeday intervals. We identified each session by a unique sequence number. Because of some technical glitches in AWS, we had to exclude certain sequences in which only partial data were collected. For example, during several sessions, AWS did not respond to our queries or was offline and we were therefore only able to process partial or no data during these sessions. In total, we obtained 26 batches of review and item-level data.

Table 3 provides summary statistics for our panel data. The data include some very popular books, such as Freakonomics: A Rogue Economist Explores the Hidden Side of Everything by Steven D. Levitt; and popular DVDs, such as The Simpsons and Star Wars. On Amazon.com, consumers can only report an integer product review on a 1-star to 5-star scale, where 1-star $=$ least satisfied and 5-star $=$ most satisfied. The average review scores for books and DVDs, are 3.87 and 4.07 respectively. Instead of providing the actual sales number, Amazon.com provides the sales rank information of the item. Product sales rank is shown in descending order where 1 represents the best selling product. Consequently, there is a negative correlation between product sales and sales rank. However, from information content prospective, the magnitude of the sales rank can be used as a proxy for the magnitude of product sales. Henceforth, unless stated differently, whenever we refer to change in sales, it represents a change in sales rank.

\section{Table 3: Summary Statistics}

\begin{tabular}{|ccccc|}
\hline \multicolumn{5}{c|}{ Amazon Data (July 2005 - Jan 2006) } \\
\hline Category & \#Reviews & \#Amazon Items & \#Distinct Items & Avg_Rating \\
\hline Book & $6,759,764$ & 261,187 & 10,052 & 3.87 \\
\hline DVD & $4,056,340$ & 258,736 & 9,988 & 4.07 \\
\hline
\end{tabular}




\subsection{Results}

Table 4: Regression Result of the Private Information Acquisition Model

\begin{tabular}{|c|c|}
\hline Dependent Variable & $\begin{array}{c}\text { Information Acquisition Model } \\
\mid \text { LogPriceChg } \mid \mathrm{t}\end{array}$ \\
\hline $\mid$ LogSaleRankChg $\left.\right|_{t-1}$ & $\begin{array}{c}0.0507 \\
(1.59,0.0561 *)\end{array}$ \\
\hline $\mid$ AvgRatingChg $\left.\right|_{t-1}$ & $\begin{array}{c}0.2467 \\
(0.51,0.3068)\end{array}$ \\
\hline LogSilence $_{\mathrm{t}-1}$ & $\begin{array}{c}0.0551 \\
(1.85,0.0324 * *)\end{array}$ \\
\hline $\log \mathrm{T}_{\mathrm{t}-1}$ & $\begin{array}{c}-0.0111 \\
(-0.62,0.2662)\end{array}$ \\
\hline $\mid$ LogSaleRankChg $_{\mathrm{t}-1} *$ LogSilence ${ }_{\mathrm{t}-1}$ & $\begin{array}{c}-0.0079 \\
\left(-2.05,0.0201^{* *}\right)\end{array}$ \\
\hline $\mid$ AvgRatingChg $\left.\right|_{\mathrm{t}-1} * \operatorname{LogSilence}_{\mathrm{t}-1}$ & $\begin{array}{c}0.0815 \\
(0.62,0.2684)\end{array}$ \\
\hline$|\operatorname{LogSaleRankChg}|_{\mathrm{t}-1} * \log \mathrm{T}_{\mathrm{t}-1}$ & $\begin{array}{c}0.0080 \\
(-3.63,0.0002 * * *)\end{array}$ \\
\hline $\mid$ AvgRatingChg $\left.\right|_{\mathrm{t}-1} * \log \mathrm{T}_{\mathrm{t}-1}$ & $\begin{array}{c}-0.0288 \\
(-0.27,0.3922)\end{array}$ \\
\hline Dvddummy & $\begin{array}{c}-0.7708 \\
\left(-23.81,<.0001^{* * *}\right) \\
\end{array}$ \\
\hline $\begin{array}{l}\mathrm{N} \\
\mathrm{R} 2\end{array}$ & $\begin{array}{l}16430 \\
0.0755\end{array}$ \\
\hline
\end{tabular}

We estimated Model 1 using ordinary least square (OLS) and reported the results in Table 4. It seems that absolute sales change has information content to vendors in terms of helping them make price adjustment, but not absolute rating change.

The coefficient before $|\operatorname{LogSaleRankChg}|^{*} \log [$ Silence $]$ is significant negative (Para=-0.0079 and P-value $=0.0201$ ), indicating that vendors selling more popularity (less Silence) items are more likely to engage on pre-announcement private information gathering to make the price adjustment, and the private information acquisition before information release dominates the price rigidity (supporting hypothesis 3 ). If there is no pre-announcement private information acquisition before releasing online reviews, then the price rigidity effect will make the coefficient before $\mid$ LogSaleRankChg $\left.\right|^{*} \log [$ Silence] be positive. While the positive coefficient before $\log [$ Silence $](\mathrm{Para}=0.0551$ and $\mathrm{P}=0.0324)$ indicates that adding 
together, the precision of pre-announcement public information effect and the price rigidity effect, outperforms the private information acquisition within events (See table 2A).

According to table $2 \mathrm{~B}$, if there is no price rigidity and the precision of public information, the coefficients before $|\operatorname{LogSaleRankChg}|{ }^{*} \log [\mathrm{T}]$ and $\log [\mathrm{T}]$ should all be negative with the increase on the value of $\log [\mathrm{T}]$ because for the same items, the longer it stays on Amazon market, the less motivated a vendor will engage on private information gathering to make the price adjustment. At the same, as time elapses, public information becomes more accurate and is more aligned toward the actual quality of a product. Thus, comparing to a newly released item, the same magnitude of review change or sales change for an aged item will be less informative because it includes less extra information, hence, resulting in a even smaller price movement. However, due to the positive force exerted by price rigidity with elapsed time, the relation between Price change and Time becomes more complex. First, the coefficient before $|\operatorname{LogSaleRankChg}| * \log [\mathrm{T}]$ is significant positive $(\mathrm{Para}=0.0080$ and $\mathrm{P}$-value $=0.0002)$, indicating that the price rigidity dominates the private information acquisition before announcement. Furthermore, the coefficient before $\log [\mathrm{T}]$ (Para $=-0.0111$ and $\mathrm{P}=0.2622$ ) is negative but not significant. This is because, as time goes by, besides the negative private information acquisition effect, there is also the negative public information precision effect. The positive price rigidity can't dominate the above two factors-the private information acquisition and the public information precision, resulting in an insignificant coefficient before $\log [\mathrm{T}]$. To summarize, we document that absolute sales change is informative about vendors' price adjustment decision; however, absolute rating change has no information contents about vendors' price movement. Furthermore it is more likely for vendors selling more popularity item to engage on pre-announcement private information acquisition. 


\section{Are consumers and vendors learning from each other-Portfolio Analysis?}

In previous section, we document whether vendors are learning from both public and private channels to make pricing adjustment decision, and what type of vendors are more likely to engage on private information acquisition. However, the above regression with un-signed variable can only show the information content of our variables, without being able to reveal exactly how vendors make price adjustment decision. Furthermore, as elaborated in our introduction, there are two sides of the learning equation: vendors (pricing decision) and consumers (purchasing and rating decision). We suspect that there is dynamic learning between these two groups. However, to get started, following the tradition, in section 3.1 we ignore such dynamic learning nature and estimate the consumer learning behavior and vendor learning behavior separately by assuming an uni-direction between rating and price, or price and rating (Figure 3). In section 3.2, we investigate this phenomenon using more sophisticated system equations to study the inter-dependent consumer learning and vendors learning simultaneously to check whether the results are different.

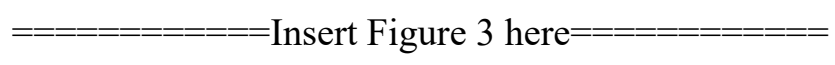

Fig 3 Uni-Relationship between Rating and Price

\subsection{Portfolio Analysis}

Before we present our system equation results, let's first show some results based on portfolio analysis to enlighten whether consumers change their belief (rating) when vendors change their prices; and whether vendors change their price in response to consumers' rating change. As Figure 3 illustrates, we separate these two learning process and measure them separately. Portfolio approach is commonly used in the accounting and finance literatures to study whether stock market participants understand information value of some phenomena. Hu et al. (2008) adopt a portfolio approach to assess the effectiveness of the online review market. They show that consumers understand the value difference between favorable news portfolio and unfavorable news portfolio and respond accordingly. The meaning of a portfolio in this context is different from a traditional finance context, where a portfolio represents a basket of securities, 
typically designed to reduce risk. Here the portfolio comprises products and events (pricing increase versus price decrease; or rating increase versus rating decreasing) sharing similar characteristics.

To document whether vendors adjust price based rating, we separate items and events into two groups: the rating increase and decrease group. The rating increase (decrease) group includes events where average consumer rating increase (decrease) from time t-2 to time $\mathrm{t}-1$. Under such a circumstance, we investigate for these two groups of items, on average, from time t-1 to t, whether the rating increasing group enjoys a significant higher future price change (from t-1 to t) than the rating decreasing group (from t-1 to t). If that is indeed the case, we conclude that vendors do adjust their price in responding to rating change.

To study whether consumers adjust their rating when vendors change their price, the consumer learning effect, those items whose price increases (decreases) from time t- 2 to time $\mathrm{t}-1$ are classified into the price increasing (decreasing) group. By comparing the future average rating change (from t-1 to t) of the price increasing group to that of the price decreasing group, we can document the existence of consumer learning.

Table 5A presents the vendor learning results. It shows that for the items of rating decreasing portfolio, on average, in the future (from time t- 1 to $t$ ), their prices decrease $\$ 0.018$; while for the items of rating increase portfolio, on average, their prices increase $\$ 0.0102$. However, the price change difference between these two groups are not significant ( $\mathrm{Para}=-0.029$ and $\mathrm{P}-\mathrm{Value}=0.6772$ ). It seems that to some degree that vendors do increase the price when the rating goes up, and decrease price while the rating goes down. However, statistically we cannot document that. Furthermore, to tease out the potential confounding influence of the popular of a product on the price movement, we classify our items into 4 equal spaced groups based on product sales ranks at time t-1 and repeat the same analysis (Table 5A). Group 1 includes items with the least sales rank, thus the best sales. And it shows that regardless of the sales of the items, there is no significant future price change difference between the rating decrease group 
and rating increase group. Thus based on portfolio method, it seems that vendors do not change price in response to rating.

Table 5A: Given the Rating Change Check the Future Price Change

\begin{tabular}{c|cc|cc|cc}
\hline \multirow{2}{*}{ Group } & \multicolumn{2}{|c|}{ Rating Decline Group } & \multicolumn{2}{c|}{ Rating Increase Group } & \multirow{2}{*}{$\begin{array}{c}\text { Price Change } \\
\text { Difference }\end{array}$} & P-Value \\
\cline { 2 - 4 } & $\mathrm{N}$ & $\begin{array}{c}\text { Average } \\
\text { Price Change }\end{array}$ & $\mathrm{N}$ & $\begin{array}{c}\text { Average } \\
\text { Price Change }\end{array}$ & & \\
\hline All & 1615 & -0.0180 & 1738 & 0.0102 & -0.0290 & 0.6772 \\
1 & 383 & -0.0050 & 455 & 0.0637 & -0.0690 & 0.6293 \\
2 & 399 & 0.0016 & 439 & -0.0040 & 0.0052 & 0.9804 \\
3 & 406 & -0.1150 & 433 & 0.0008 & -0.1160 & 0.1108 \\
4 & 427 & 0.0436 & 411 & -0.0240 & 0.0677 & 0.3649 \\
\hline
\end{tabular}

Table 5B: Given the Price Change Check the Future Rating Change

\begin{tabular}{|c|c|c|c|c|c|c|}
\hline \multirow{2}{*}{ Group } & \multicolumn{2}{|c|}{ Price Decline Group } & \multicolumn{2}{|c|}{ Price Increase Group } & \multirow{2}{*}{$\begin{array}{l}\text { Rating Change } \\
\text { Difference }\end{array}$} & \multirow{2}{*}{ P-Value } \\
\hline & $\mathrm{N}$ & $\begin{array}{c}\text { Average } \\
\text { Rating Change }\end{array}$ & $\mathrm{N}$ & $\begin{array}{c}\text { Average } \\
\text { Rating Change }\end{array}$ & & \\
\hline All & 7818 & -0.0020 & 7859 & -0.0010 & -0.0005 & 0.6394 \\
\hline 1 & 1916 & -0.0030 & 2003 & -0.0010 & -0.0010 & 0.5105 \\
\hline 2 & 1946 & -0.0030 & 1973 & -0.0010 & -0.0020 & 0.5648 \\
\hline 3 & 2051 & -0.0010 & 1869 & -0.0030 & 0.0017 & 0.4733 \\
\hline 4 & 1905 & -0.0010 & 2014 & -0.0003 & -0.0008 & 0.6047 \\
\hline
\end{tabular}

Table 5B presents the results of whether consumers adjust their rating in response to the price change with and without the popularity of items get controlled. Same as vendor side learning, comparing to the items received a increasing price from time $\mathrm{t}-2$ to $\mathrm{t}-1$, for items received a decreasing price within that period, on average, they do not enjoy a better future consumer rating (difference $=-0.0005 \mathrm{P}$ value $=0.6394$ ), failing to support the claim that consumers might give a better rating if vendors lower their price. We reach the same conclusion when we control the sales of the item as well (please refer to the results of group 1, 2, 3, and 4 in Table 5B for details)

\subsection{System Equation}


Our simple portfolio analyses did not find evidences that vendors or consumer are learning from each other to make the price or rating decision. Is that really true? As we state before, due to the systematic, dynamic, and bi-direction nature of the vendor and consumer learning, estimating these two learning processes separately might not reveal the underlying learning processes because the price, reviews, and sales are jointly determined by each other. To address such an issue, we turn to system equation using limited information maximum likelihood estimation ${ }^{1}$.

Figure 4 describes this dynamic learning pattern. At the first stage, vendors set up an initial price to start this game (Stage 1 in Figure 4), based on public information (such as price), private information, or online reviews (if available), consumers make purchase decision (stage 2). Based on the observed reviews, sales, or other private information, vendors make the necessary price adjustment (stage 3 ). The changing price might influence the sales at stage 4 , henceforth, resulting in change of review at stage 5 because the new price might attract a different segment of customers. Please be aware that the time $t$ is in the relative sense.

Figure 4 also shows that the direction between rating and price are bi-direction, and there are both direct and indirect impacts between these two variables. On the vendor learning side, rating might directly influence vendors pricing decision (direct impact); or rating might achieve that goal through the mediation of demand (indirect impact); On the consumer learning side, a decreasing price might either directly improves future consumer ratings (direct impact); or indirectly boosts consumer reviews through stimulating the demand (indirect impact) by bringing another segment of customers.

$=========$ Insert Figure 4 here $=========$

Fig 4 Double-Learning Research Model

\subsubsection{Empirical Regulation of Double Learning}

Equation 1: Vender Learning:

${ }^{1}$ This estimation is available through SYSLIN procedure in SAS. Qualitatively, the results do not change when we use 2SLS. 


$$
\begin{aligned}
& \log [\text { Price }]_{\mathrm{it}}= \begin{array}{c}
\alpha_{0}+\alpha_{1} \log [\text { SalesRank }]_{\mathrm{it}-1}+\alpha_{2} \log [\text { Price }]_{\mathrm{it}-1}+\alpha_{3} \text { Avgrating }_{\mathrm{it}-2} \\
+
\end{array} \\
&+\alpha_{4} \log \left[\text { Silence }_{\mathrm{it}-1}+\alpha_{5} \log [\mathrm{T}]_{\mathrm{it}-1}+\alpha_{6} \text { HelpRatio }_{\mathrm{it}-1}+\alpha_{7} \text { DvdDummy }_{\mathrm{i}}+\varepsilon_{\mathrm{it}}^{\prime}\right.
\end{aligned}
$$

Equation 2: Demand Function:

$$
\begin{aligned}
\log [\text { SalesRank }]_{\mathrm{it}-1}= & \beta_{0}+\beta_{1} \log [\text { SalesRank }]_{\mathrm{it}-2}+\beta_{2} \log [\text { Price }]_{\mathrm{it}-2}+\beta_{3} \text { Avgrating }_{\mathrm{it}-2} \\
& +\beta_{4} \log [\text { Silence }]_{\mathrm{it}-2}+\beta_{5} \log [\mathrm{T}]_{\mathrm{it}-2}+\beta_{6} \text { HelpRatio }_{\mathrm{it}-2}+\beta_{7} \text { DvdDummy }_{\mathrm{i}}+\varepsilon_{\mathrm{it}-1}^{\prime \prime}
\end{aligned}
$$

Equation 3: Consumer Learning:

$$
\text { Avgrating }_{\mathrm{it}}=\begin{gathered}
\gamma_{0}+\gamma_{1} \text { Avgrating }_{\mathrm{it}-1}+\gamma_{2} \log [\text { SalesRank }]_{\mathrm{it-1}}+\gamma_{3} \log [\text { Price }]_{\mathrm{i}-2} \\
+\gamma_{4} \log [\text { Silence }]_{\mathrm{it}-1}+\gamma_{5} \log [\mathrm{T}]_{\mathrm{it}-1}+\gamma_{6} \text { HelpRatio }_{\mathrm{it}-1}+\gamma_{7} \text { DvdDummy }_{\mathrm{i}}+\varepsilon_{\mathrm{it}}^{\prime \prime \prime}
\end{gathered}
$$

Where

$\log [\text { SalesRank }]_{i t}=$ the natural log of sales rank for the $i^{\text {th }}$ product at time $t$.

$\log [\text { Price }]_{i t}=$ the natural $\log$ of price for the $\mathrm{i}^{\text {th }}$ product at time $\mathrm{t}$.

Avgrating $_{\mathrm{it}}=$ the average rating for the $\mathrm{i}^{\text {th }}$ product at time $\mathrm{t}$.

$\log [\text { Silence }]_{i t}=$ the natural $\log$ of the Silence of the $i^{\text {th }}$ product at time $t$, where

Silence $=\mathrm{T} /$ Number of Reviews , smaller $\log [\text { Silence }]_{i t}$ value represents items with higher popularity.

$\log [\mathrm{T}]_{\mathrm{it}}=$ How long the $\mathrm{i}^{\text {th }}$ product has been released to Amazon market at time $\mathrm{t}$.

HelpRatio $_{i t}=\sum_{\mathrm{j}=1}^{\mathrm{N}}$ Helpful_Vote $_{\mathrm{j}} / \sum_{\mathrm{j}=1}^{\mathrm{N}}$ Total_Vote $_{\mathrm{j}}$, this variable is used to measure out of all the N number of reviews item i received till time t, on average, how helpful are these reviews.

We expect the signs of the estimated coefficients to be:

- $\beta_{2} * \gamma_{2}<0\left(\beta_{2}>0\right.$ and $\left.\gamma_{2}<0\right)$, indicating negative indirect price effect. When the vender charges a lower price, the demand of this product increase (Sales rank declines). And the lower price attracts a new segment of customers, resulting in a lower review rating.

- $\beta_{3} * \alpha_{1}>0\left(\beta_{3}<0\right.$ and $\left.\alpha_{1}<0\right)$, indicating positive indirect Rating effect. When the consumers give higher rating, the good reviews will lead to a higher demand (Sales rank becomes smaller), and then this will encourage the vender charge a higher price to maximize its profit. 
- $\quad \alpha_{3}>=0$ (Direct rating effect) When $\alpha_{3}>0$ measures the directly impact of rating to vendors' pricing adjustment decision. It reveals the venders learning effect, that is, vendors directly respond to consumers' reviews to adjust their price. But if the venders think the Average Rating might be manipulated, they will make their pricing adjustment decision based on the demand (Sales Rank). Under such a circumstance, $\alpha_{3}=0$

- $\quad \gamma_{3}<=0$ (Direct pricing effect). When $\gamma_{3}<0$ means consumers will change their evaluation according to the Price. It reflects that consumers directly respond to vendors' price adjustment movement to change their online reviews. But if consumers are smart, they will not change their rating in response to vendors' price adjustment, hence $\gamma_{3}=0$. Under such a circumstance, the price only impact rating through demand.

In order to test the significance of the indirect price and rating effects through the demand (Sales Rank), we calculated the t-value according to Sobel (1982). For example, to test the indirect price effect, we estimate the $t$ as $\left(\beta_{2} * \gamma_{2}\right) / \sqrt{\beta_{2}{ }^{2} * S_{\beta_{2}}^{2}+\beta_{1}{ }^{2} * S_{\beta_{1}}^{2}}$ (where $S_{\beta_{2}}^{2}$ is the standard error of the estimated coefficient).

\subsubsection{Empirical Results}

Table 6 presents the limited-information maximum likelihood (LIML) estimation of our double learning model. Asymptotically two stage least square (2SLS) and LIML estimators had the same distribution (Anderson 2005). Even though it is much easier to compute the 2SLS, LIML was considered to be advantageous than 2SLS due to the following three reasons:

1) The parameter estimation method of simultaneous equation models was based on using maximum likelihood. And it is commonly believed that the maximum likelihood method yields superior estimators (Anderson 2005);

2) LIML takes into account of the covariances of the errors; 
3) 2 SLS estimator treats the components of $\beta$ asymmetrically and that was contrary to the point of view of simultaneous equations (Page 9 Anderson 2005).

We estimate the system equation using Proc Syslin and present the results in Table 6. We obtained the condition index to detect the existence of multicollinearity and found that our conditional index is smaller than 15 , thus we conclude for our data, multicollinearity is not a serious concern here. Furthermore, we check serial correlation with DW test. Since our DW value is 1.405 , we can also reject the existence of serial correlation.

For the vendor side learning (the price equation), the direct impact of online reviews on sales is not significant $($ Para $=0.0000$ and $\mathrm{P}$-value $=0.9622$ ), indicating that vendors do not adjust their price by simply responding to the review change. $\beta_{3}$ is significant negative (Para $=-0.0380$ and $\mathrm{P}$-value $<=0.0001$ ), while $\alpha_{1}$ is also significant negative (Para $=-0.0095$ and $\mathrm{P}$-value $\left.<=0.0001\right)$. Combining them together, $\beta_{3}$ ${ }^{*} \alpha_{1}$ is significant positive ( $\mathrm{Para}=0.0004$ and $\mathrm{P}$-value $<=0.10$ ), indicating that rating only indirectly impact vendors' pricing decision through sales (Figure 5). For the consumer side learning (Rating Equation in Table 6), we reach a similar conclusion that pricing only indirectly impacts consumer reviews through sales because 1) $\gamma_{3}$ (direct impact) is not significant different from zero(Para $=-0.0016$ and Pvalue $=0.4867) ; 2) \quad \beta_{2}$ is significant positive $(\operatorname{Para}=0.0139$ and $\mathrm{P}$-value $=0.0943)$ and $\gamma_{2}$ is significant negative $(\mathrm{Para}=-0.0417$ and $\mathrm{P}$-value $<=0.01)$; and 3) $\beta_{2} * \gamma_{2}$ is significant negative ( $\mathrm{Para}=0.0006$ and $\mathrm{P}$ value $<=0.01$ ). Figure 5 summarizes the results for our double-learning model. As we can see, this is a full demand-mediation model because the impact of rating on price (the vendor learning) as well as the impact of price on rating (the consumer learning) are all through demand.

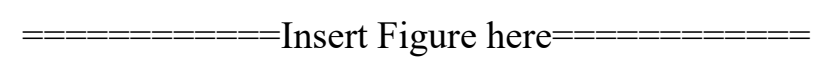

Fig 5 Double-Learning Results: Full Demand-Mediation Relationship 
Table 6 Result of LIML Estimation of Double Learning Model

\begin{tabular}{|c|c|c|c|}
\hline & $\begin{array}{c}\text { Vender Learning } \\
\left(\text { Log }^{\text {Price }}{ }_{t}\right)\end{array}$ & $\begin{array}{l}\text { Demand Function } \\
\left(\text { Log SalesRank }_{t-1}\right)\end{array}$ & $\begin{array}{c}\text { Consumer Learning } \\
\text { (Avgrating } t)\end{array}$ \\
\hline Log SalesRank $_{t-1}$ & $\begin{array}{c}-0.0095 \\
(-35.85,<.0001 * * *)\end{array}$ & \multirow[b]{2}{*}{$\begin{array}{c}0.9268 \\
(389.87,<.0001 * * *)\end{array}$} & $\begin{array}{c}-0.0417 \\
(-62.6,<.0001 * * *)\end{array}$ \\
\hline $\begin{array}{c}\text { Log } \text { SalesRank }_{t-2} \\
\text { Log Price }_{t-1}\end{array}$ & $\begin{array}{c}0.9939 \\
(1076.74,<.0001 * * *)\end{array}$ & & \multirow{4}{*}{$\begin{array}{c}\mathbf{- 0 . 0 0 1 6} \\
\mathbf{( - 0 . 7 0 , 0 . 4 8 6 7 )} \\
0.9434 \\
(473.99,<.0001 * * *)\end{array}$} \\
\hline Log Price $_{t-2}$ & & $\begin{array}{c}0.0139 \\
(1.67,0.0943 *)\end{array}$ & \\
\hline Avgrating $t-1$ & & & \\
\hline Avgrating $_{\mathrm{t}-2}$ & $\begin{array}{c}0.0000 \\
(\mathbf{0 . 0 5}, \mathbf{0 . 9 6 2 2})^{\#}\end{array}$ & $\begin{array}{c}-0.0380 \\
(-5.34,<.0001 * * *)\end{array}$ & \\
\hline Log Popularity $_{t-1}$ & $\begin{array}{c}0.0013 \\
(2.80,0.0051 * * *)\end{array}$ & & $\begin{array}{c}0.0033 \\
(2.93,0.0034 * * *)\end{array}$ \\
\hline Log Popularity $_{\mathrm{t}-2}$ & & $\begin{array}{c}0.0609 \\
(14.9,<.0001 * * *)\end{array}$ & \\
\hline $\log T_{t-1}$ & $\begin{array}{c}-0.0010 \\
(-2.28,0.0228 * *)\end{array}$ & & $\begin{array}{c}0.0002 \\
(0.21,0.8326)\end{array}$ \\
\hline $\log T_{t-2}$ & & $\begin{array}{c}-0.0300 \\
(-7.63,<.0001 * * *)\end{array}$ & \\
\hline HelpRatio $_{t-1}$ & $\begin{array}{c}0.0050 \\
(1.42,0.1547)\end{array}$ & & $\begin{array}{c}0.0044 \\
(0.49,0.6230)\end{array}$ \\
\hline HelpRatio $_{t-2}$ & & $\begin{array}{c}-0.0573 \\
\left(-1.8,0.0717^{*}\right)\end{array}$ & \\
\hline DVD Dummy & $\begin{array}{c}-0.0024 \\
(-2.26,0.0236 * *)\end{array}$ & $\begin{array}{c}-0.0519 \\
(-5.52,<.0001 * * *)\end{array}$ & $\begin{array}{c}-0.0059 \\
(-2.23,0.0256)\end{array}$ \\
\hline $\mathbf{N}$ & 21918 & 21918 & 21918 \\
\hline $\mathbf{R}^{2}$ & 0.98285 & 0.9191 & 0.9271 \\
\hline $\begin{array}{l}\text { Indirect Effect } \\
\text { (Rating->Price) }\end{array}$ & $\begin{array}{r}(-0.0380) *(- \\
(1 .\end{array}$ & $\begin{array}{l}\text { 95) }=0.0004 \\
5 *)\end{array}$ & \\
\hline $\begin{array}{l}\text { Indirect Effect } \\
\text { (Price->Rating) }\end{array}$ & & $\begin{array}{r}0.0139 *(-0.0 \\
(-4.89\end{array}$ & $\begin{array}{l}\text { 7) }=-0.0006 \\
* * *)\end{array}$ \\
\hline
\end{tabular}

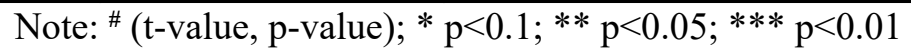

\section{Implications, Limitations and Future Research}

As online reviews are becoming an increasingly important source of information for consumers purchase decisions, there is an urgent need to bring in the long-over-look vendor side learning into equation. It is timely and important to understand how consumers are making purchase decision, how vendors are 
making price adjustment decision, and how consumers and vendors are learning from each other. Furthermore, it is vital to find out whether vendors are acquiring information from both public and private information channels to make pricing adjustment decision, what kind vendors are more likely to engage on private information acquisition activities, and based on what signals vendors are making price adjustment. This paper contributes to the emerging literature on online reviews by addressing these fundamental but largely neglected questions.

In this study, we bring in the information acquisition theory from capital market and consider the distinctive public and private information channels in which product price and quality information can be gathered. We find evidences that vendors are actively acquiring private information channels to help them make the right price adjustment. Vendors selling the more popular items and the newly released item are more inspired to gather private information. Thus given the same magnitude of rating change, it is more likely for these types of vendors to adjust price with a bigger amount. For the more popular items and at the early stage of marketing, online consumer review market provides limit information for these vendors to make pricing decision. Thus, they turn to private channels to collect further information to help them make the appropriate pricing decision. However, we also document that even without the rating change, depending on the popularity and the age of an item, the price adjustment vendors made also vary. That variation is determined by the net effect of the precision of the public information before announcements, the amount of pre-announcement private information acquisition, and the price rigidity. Vendors might be able to utilize the above learning effects to predict future price change of their competitors, while consumers can forecast the price of the items they are interested. As a result, vendors and consumers can make better decisions on when to enter the market if at all.

Through sophisticate system equations, we are able to unveil the complicate simultaneous learning processes between consumer and vendor. Surprisingly we find that contrary to a common wisdom, online vendors do not respond directly to online reviews; however, the impact of online reviews is indirect through sales. Vendors do not respond to review change unless that review change does impact sales. On the other hand, consumers are smart and they do not respond directly to the pricing change 
made by the vendor as well. In other words, when facing a decreasing online consumer reviews, vendors cannot simply change the price in the hope of getting better sales through receiving better reviews because lowering a product price will not enable a vendor to get better consumer reviews directly. However, eventually decreasing price does help because it brings in a different segment of customers.

Putting consumers and vendors together, we document a full demand-mediation model between rating and price, which is there is no direct linkage between price and rating. The impact of rating on price (the vendor learning) as well as the impact of price on rating (the consumer learning) are all through demand.

Two potential explanations might be able to account for the above observations: 1) the impact of reviews has been incorporated into sales; 2) Even with the fast adoption and increasingly importance of online reviews, pricing decision with or without the presence of online reviews maintains the same. Online reviews just provide another channel that vendors can utilize to understand their customers better and faster. The pricing is still simple driven by the relation between supply and demand. Vendors will only adjust the price when they see a decreasing demand. The reason for that might originate from the trustworthy issue of online reviews. Online reviews might be manipulated because actual customers, online vendors themselves, online vendors' competitors, publishers, and authors are all able to write "consumer" reviews. So vendors will not responds to online reviews change unless such a change is material and results in actionable consequence, the sales change (demand). So what are these vendors betting on? We believe the answer lies on the smartness of the consumers. As we show that the change on the product price has no direct impact on consumer rating either. Consumers are wise and their evaluations are not directly influenced by the change of product price. Furthermore, Dellarocas (2006) analytically shows even with manipulation, consumers are smart and can adjust their interpretation of online opinions accordingly. Putting all these together, vendors make the right decision by not simply responding to review change as well. They are waiting for consumers' movement before making the final price adjustment.

We believe that our findings have significance in practice. As more and more consumers turn to the Internet for product information, vendors turn to online channel for increasing sales. Online consumer 
reviews have become a significant force to influence the purchase decision of consumers as well as the pricing decision of vendors. However, vendors should be educated to better manage online information channel so as to unveil the consumer's personal assessment of product. Vendors should not try to manipulate the online reviews in the hope of gaining better sales. Online reviews are not silver bulletin, and not all online reviews are created equally. Vendors should not write fake online reviews blindly or adjust their pricing thoughtlessly.

This research has certain limitations that warrant our attention as they offer new avenues for further research. First, the data set used for this research is slightly old. Although we believe this has no impact on our findings, future research can consider re-validating our research with newer data. Second, our study does not consider the intrinsic difference among various sub-product categories within Book or DVD category. For example, vendor should follow different price adjustment strategies based on whether the quality of their products is more subjective or objective. For items with more objective valuation, vendors should be very cautious about making pricing adjustment because 1) reviews for these objective items are relative stable; 2) even with the presence of some bad reviews posted by consumers or competitors, given the more objective nature of this type of goods, future customers will be less likely to be influenced by the bad reviews. And the later authentic consumer reviews will come in and correct such a bias. Third, contrary to common wisdom, we were not able to document the direct relationship between the pricing and rating. We interpret this as rational behaviors taking by both vendors and consumers due to potential online manipulation. However, the picture might be much worse than what we just painted. Even though both vendors and consumers sit right across table, it seems that neither of them really listens to each other. To some degree they are totally blind to the other party and the messages sent right across the table are all considered as non-trustworthy. Somehow demand becomes a trusted agent because only the information flow through demand becomes dependable and actionable. Is this really driven by the manipulation behavior or this is driven by Amazon sample? Why do vendors ignore the rich meaning of these online reviews? Are vendors and consumers under-responding? Why do consumers not giving a better rating when the price decreases? Future research focusing on one specific subject topic of book or 
DVD and utilizing datasets from different websites and at different time-periods may lead to more interesting findings in vendor learning. Before that happen, we leave the question to our readers, which side of the story do you believe, the double learning or double blinding?

\section{References}

Amrouche, N. and Yan, R., 2015. A manufacturer distribution issue: how to manage an online and a traditional retailer. Annals of Operations Research, 1-38.

Ancarani, F., and Shankar, V. (2002). Price levels and price dispersion: A comparison of pure play vs. bricks-and-mortar vs. bricks-and-clicks e-tailers. Working Paper, SDA Bocconi, Milan, Italy.

Anderson, T.W. (2005). Origins of the limited information maximum likelihood and two-stage least squares estimators ,Journal of Econometrics, 127(1), 1-16.

Atiase, R. (1980). Predisclosure Informational Asymmetries, Firm Capitalization, Financial Reports, and Security Price Behavior. Ph.D. dissertation, University of California, Berkeley.

Bailey, J.P. (1998), Electronic commerce: Prices and consumer issues for three products: Books, compact discs, and software, Organization for economic co-operation and development, $O C D E / G D$ vol. 98 (1998), p. 4.

Baltagi, B.H. (2001) Econometric Analysis of Panel Data (Second ed.). Chichester: John Wiley \& Sons.

Bergen, M.E., Kauffman, R.J., and Lee, D. (2005). Beyond the Hype of Frictionless Markets: Evidence of Heterogeneity in Price Rigidity on the Internet, Journal of Management Information Systems, 22(2), 57-89.

Boulding, W. (1990). Unobservable effects and business performance: Do fixed effects matter? Marketing Science, 9(1), 88-91.

Brynjolfsson, E., and Smith, M. (2000), Frictionless commerce? A comparison of Internet and conventional firms, Management Science 46 (4), 563-585.

Cortese and M. Stepanek (1998), Good-bye to fixed pricing? How electronic commerce could create the most efficient market of them all, Business Week (May 4), pp. 71-84.

Chevalier, J. \& Mayzlin, D. (2006). The Effect of Word of Mouth on Sales: Online Book Reviews. Journal of Marketing Research, 43(3), 345-354.

Chen, P-Y., Wu, S-Y. \& Yoon, J. (2004). The Impact of Online Recommendations and Consumer Feedback on Sales. Proceeding of the International Conference on Information Systems, Washington, D.C., 711-724.

Chong, A.Y.L., Li, B., Ngai, E.W., Ch'ng, E. and Lee, F. (2016). Predicting online product sales via online reviews, sentiments, and promotion strategies: A big data architecture and neural network approach. International Journal of Operations \& Production Management, 36(4), 358-383.

Dellarocas, C., Awad, N. F. \& Zhang, X. (2004). Exploring the Value of Online Reviews to Organizations: Implications for Revenue Forecasting and Planning. Proceedings of the 25th International Conference on Information Systems (ICIS), Dec. 2004, Washington DC.

Dellarocas, C. (2006) Strategic manipulation of internet opinion forums: Implications for consumers and firms. Management Science, 52(10), 1577 - 1593.

Erevelles, S., Rolland, E., \& Srinivasan, S. (2001). Are prices really lower on the Internet? An analysis of the vitamin industry. Working Paper, AGSM.

Gaikar, D.D., Marakarkandy, B. and Dasgupta, C. (2015). Using Twitter data to predict the performance of Bollywood movies. Industrial Management \& Data Systems, 115(9), 1604-1621.

Godes, D., and Mayzlin, D. (2004). Using online conversations to study word of mouth communication. Marketing Science, 23 (4), 545-560.

$\mathrm{Gu}, \mathrm{B}$., and Ye, Q. (2014). First step in social media: Measuring the influence of online management responses on customer satisfaction. Production and Operations Management, 23, 570 - 582. 
Hu, N, Ling Liu, Zhang, J. (2008). Do online Reviews Affect Product Sales? The Role of Reviewer Characteristics and Temporal Effects, Information Technology and Management, 9(3), 201-214.

Jiang, Y., \& Zhao, J. (2014). Co-creating business value of information technology. Industrial Management \& Data Systems, 114(1), 53-69.

Kim, O. and R. Verrecchia. (1991). Trading volume and price reactions to public announcements. Journal of Accounting Research 29: 302-21.

Kim, O. and R. Verrecchia (1994). Market liquidity and volume around earnings announcements. Journal of Accounting and Economics 17 (1): 41-68.

Kim, O. and R. Verrecchia (1997). Pre-announcement and event-period private information. Journal of Accounting and Economics 24: 395-419.

Lee, Ho Geun, Lee, Seung Chang, Kim, Hae Young, and Lee, Ran Hui (2003), Is the internet making retail transactions more efficient? Comparison of online and offline CD retail markets. Electronic Commerce Research and Applications 2(3): 266-277.

Li, X., \& Hitt, L. M. (2008). Self-selection and information role of online product reviews. Information Systems Research, 19(4), 456-474.

Liu, Y., Li, H., Peng, G., Lv, B. and Zhang, C. (2015). Online purchaser segmentation and promotion strategy selection: evidence from Chinese E-commerce market. Annals of Operations Research, 233(1), 263-279.

Morton, F.S. , Zettelmeyer, F., and Risso, J.S. (2001). Internet car retailing, Journal of Industrial Economics, 49 (4), 501-519.

Ngai, E.W., Moon, K.L.K., Lam, S.S., Chin, E.S. and Tao, S.S. (2015). Social media models, technologies, and applications: an academic review and case study. Industrial Management \& Data Systems, 115(5), 769-802.

Schneible Jr., Richard A. and Stevens, Douglas E. (2005), "Pre-Announcement and Event-Period Private Information: A Trading Volume Analysis of Firm Size and Institutional Ownership Effects" (September 30). Available at SSRN: http://ssrn.com/abstract $=817565$

Shen, W., Hu, Y.J. and Rees, J. (2015). Competing for attention: An empirical study of online reviewers' strategic behaviors. MIS Quarterly, 39(3), pp.683-696.

Sobel, M. E. (1982). Asymptotic Confidence Intervals for Indirect Effects in Structural Equations Models, in Sociological Methodology, S. Leinhart (eds.), Jossey-Bass, San Francisco, CA, 1982, pp. 290312 . 


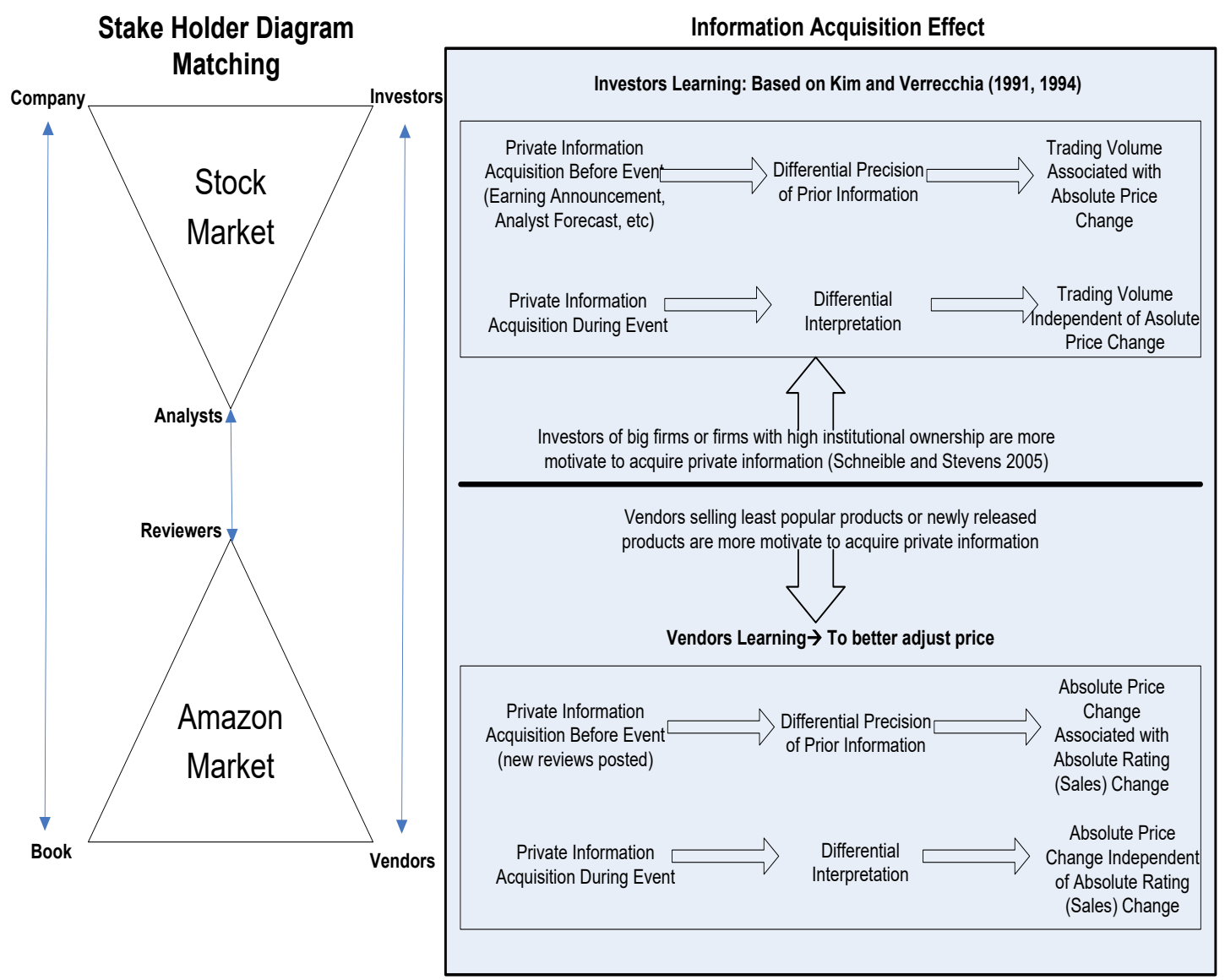

Fig 1 Information Acquisition Effect on Stock Market and Amazon Market

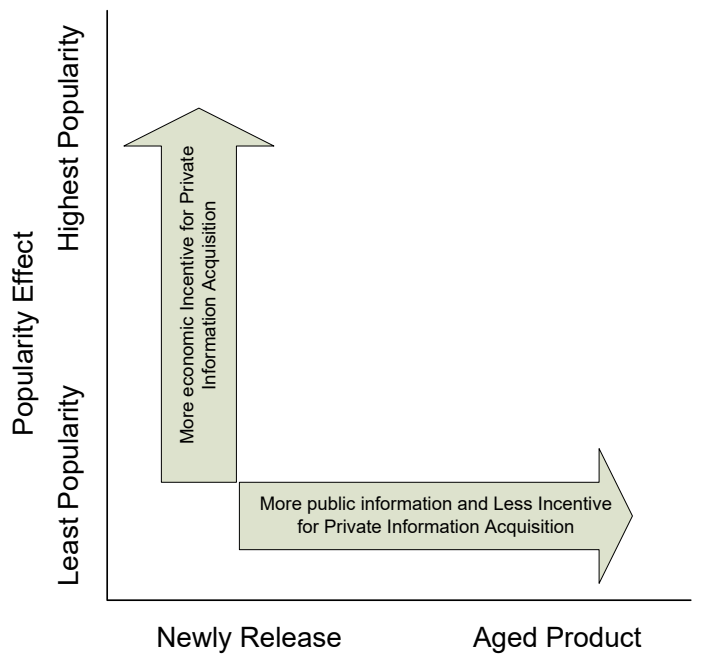

Time Effect

Fig 2 Time Learning Effect and Popularity Learning Effect 
Time 1 Time 2 Time 3

Rating $\stackrel{? \text { Price }}{\longrightarrow}$ Rating

Fig 3 Uni-Relationship between Rating and Price

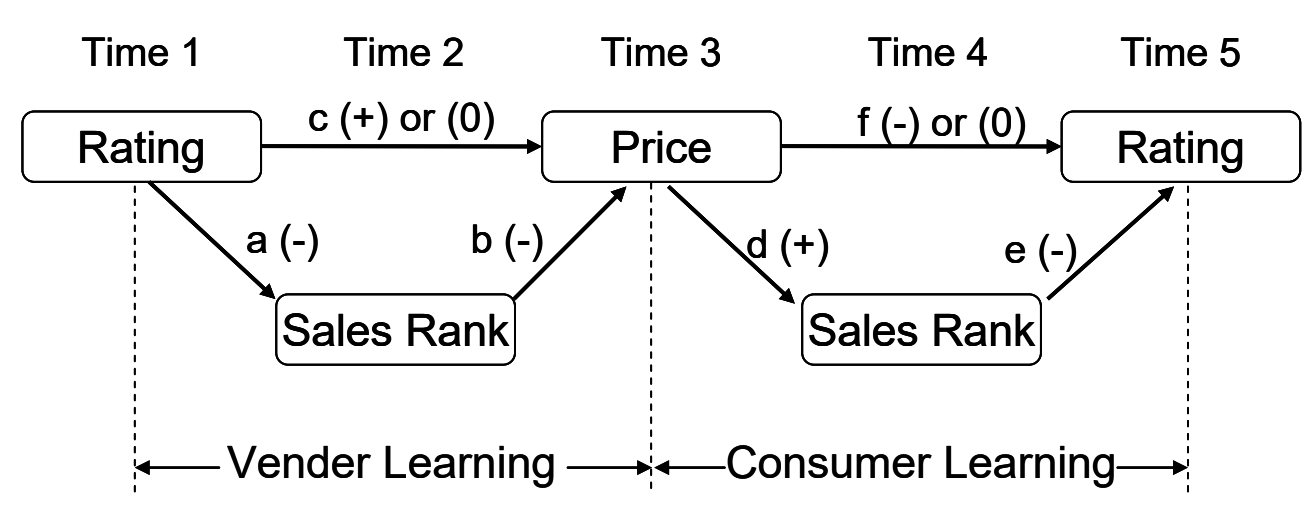

Fig 4 Double-Learning Research Model

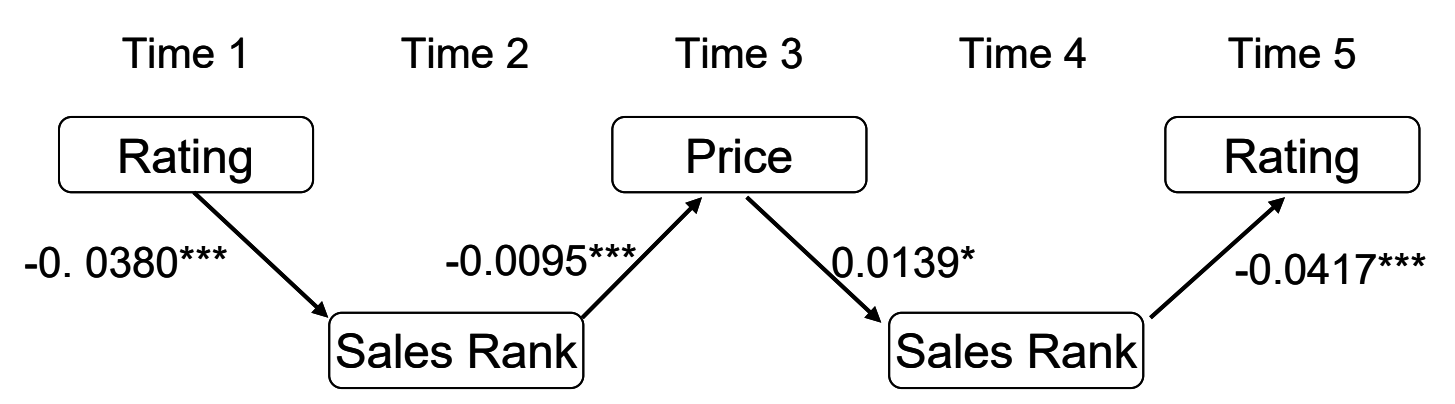

Fig 5 Double-Learning Results: Full Demand-Mediation Relationship 
